\title{
The significance of radiation-induced chromosome abnormalities in radiological protection
}

\author{
G. W. DOLPHIN and D. C. LLOYD \\ National Radiological Protection Board, Harwell, Didcot, Berkshire
}

\begin{abstract}
Summary. A brief review is given of the production and analysis of chromosome aberrations induced by ionizing radiation. The various tissues in which it is possible to demonstrate aberrations are noted and particular emphasis is laid on the culture of peripheral blood lymphocytes. Some examples of recent applications of the technique are described. These are in the determination of suspected overdoses to radiation workers, in estimating doses to radiotherapy patients, and investigating the depth/biological damage profile for a negative $\pi$ meson beam.
\end{abstract}

Although chromosome damage induced by ionizing radiation in plant material had been observed early this century, the first quantitative studies were not carried out until 1938 by Sax. He studied chromosome damage induced by $x$-rays in Tradescantia microspores observed at the first post-meiotic division where the six chromosomes, the haploid number, were clearly visible in squash preparations. During the next two decades, Sax and other workers carried out many experimental studies with plant material, mainly with species of Tradescantia. They studied how aberration yield changed with various physical and biological parameters. These included dose, dose rate, neutron and alpha particle radiation, irradiation at different stages of the cell cycle, temperature during irradiation, and the presence of oxygen. A good account of this early work was given in a review by Giles (1954). As early as 1946 sufficient results had been obtained for Lea to publish a theory of chromosome breaks which was essentially that they were caused by several ionizations produced by one ionizing particle in its passage through the chromosome or chromatid.

The study of chromosomes in human cells became possible in the middle 1950s when culture techniques and slide preparation had improved to a point where the 46 human chromosomes could be readily identified. However, the real breakthrough did

Received 15 August 1973. not occur until 1960 when Moorhead et al published a method for stimulating peripheral blood lymphocytes to divide in culture. With the availability of lymphocytes and the ease with which they could be stimulated, cultured and dispensed onto slides, these cells became the method of choice for human chromosome studies in laboratories throughout the world.

\section{Chromosome Aberrations}

Aberration Types. Two main types of aberration are observed at metaphase; chromosome type produced by irradiation during $G_{0}$ or early $G_{1}$, and chromatid type produced by irradiation after the chromosome has split into two chromatids in late $G_{1}$ and subsequent stages. In chromosometype aberrations both chromatids carry similar breaks when observed at the first metaphase following irradiation. A break in one chromatid may be replicated if the cell passes through division into the second mitosis after irradiation. The symmetrical damage introduced in this way is known as a derived chromosome-type aberration.

In tissue where cell replacement is continuously taking place radiation will induce chromosome- and chromatid-type damage, and the relative amounts visible in the cell at metaphase will depend on the time lapse between irradiation and slide preparation, as well as the sensitivity of the cell during various stages of the cycle. The considerable advantage in 


\begin{tabular}{|c|c|c|c|c|c|c|}
\hline & & & & \\
\hline
\end{tabular}

Fig. 1. Chromosome-type aberrations-intrachanges.

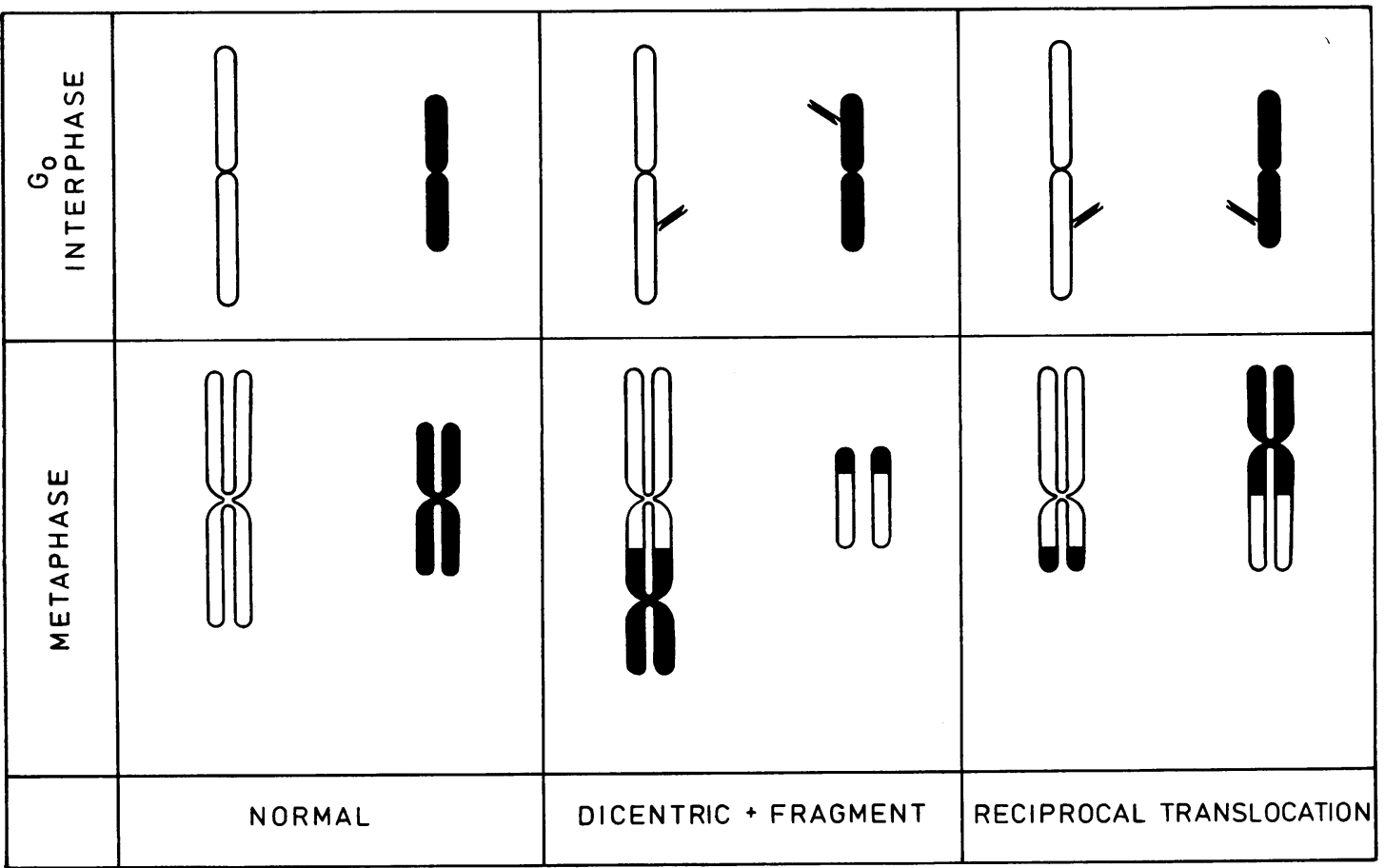

Fig. 2. Chromosome-type aberrations-interchanges. 
studying aberrations in lymphocytes is that for practical purposes all the cells are in $\mathrm{G}_{0}$ stage so that only chromosome-type damage is present. In this short review we propose to deal only with chromosome-type damage and the reader is referred to Evans (1970) for more information about chromatid damage.

Figures 1 and 2 show how chromosome-type aberrations are formed by intrachange and by interchange, respectively. The breaks produced during $\mathrm{G}_{0}$ stage are caused by ionizations during the passage of a charged particle through the chromosome. For $\mathrm{X}$ or $\gamma$ radiation absorption the charged particle is an electron, which has a low density of ionization along its track. Other particles-alpha particles and protons associated with neutron absorptionare more densely ionizing and consequently produce a higher degree of damage along the track. In the Figs. 1 and 2 the break points in the chromosomes are indicated by arrows, but this does not necessarily mean that each break is produced by a different particle track for both break points could be produced by one densely ionizing particle. In $\mathrm{G}_{0}$ stage the chromosomes consist of a long strand or strands which are probably intertwined so there is a possibility of a single track, particularly a densely ionizing one, producing several ionizations in two chromosomes or in the same chromosome at two different points.

Stable Aberrations. This classification was introduced some years ago and includes all those aberrations which can pass through cell division indefinitely. The two illustrated in Figs. 1 and 2 are pericentric inversions and translocations. As yet these aberrations have not been used in biological dosimetry because only a minority of them can be definitely identified as different from chromosomes expected in the normal karyotype. Greater efficiency in identification of these aberrations will be obtained when banding techniques (Pearson, 1972) have been thoroughly developed and coupled with automatic techniques (Green and Cameron, 1972) for analysing the chromosomes and their band patterns.

Unstable Aberrations. With this type of aberration, material may be lost from the genomes during division so that non-viable daughter cells are generally produced eventually leading to death of the cell line. The loss occurs when acentric pieces fail to attach to the spindle and when anaphase bridges are formed from dicentric aberrations. Being relatively easily observed at metaphase this type of aberration is particularly valuable in scoring for radiation dosimetry. They are usually classified into three types.
Dicentrics Plus a Fragment (see Fig. 2). These arise from a break in each of two chromosomes which wrongly rejoin to form a structure with two centromeres plus an acentric fragment. Experimental studies (Wolff, 1972; R. J. Purrott, personal communication) have shown that the two separate breaks must be produced within an interval of a few hours in order for the ends to combine to produce a dicentric. Hence $\mathbf{X}$ and $\gamma$ radiation spread out in time produce less dicentrics than the same amount of radiation delivered in a short time, but the duration is less important for the densely ionizing particles because both breaks are usually produced by one track.

Centric Rings plus a Fragment (see Fig. 1). These aberrations arise from two breaks in the same chromosome, on either side of the centromere, which rejoin wrongly to form a ring including the centromere and an acentric fragment remains. Again, like the dicentric, this aberration type can be formed by one or two tracks. The similarity in the formation of the dicentric and the centric ring has led some observers to combine these two types when reporting aberration yields.

Acentrics (see Fig. 1). Under this classification three types of aberration are grouped, namely terminal deletions, interstitial deletions, and acentric rings. In quantitative work it is necessary to group these aberrations because a clear distinction cannot be made between them, eg, a small acentric ring approaches the size and shape of an interstitial deletion and both could be confused with a small terminal deletion. The terminal deletion, in principle, could be produced by the passage of a single ionizing track through a chromosome but the others involve two breaks.

\section{Radiation Dose and Aberration Yield}

The relationship between unstable aberration yield and radiation dose has been studied in many laboratories by means of in-vitro irradiation of blood. Some typical curves for dicentric yields are given in Fig. 3 for ${ }^{60}$ cobalt $\gamma$ radiation at $18 \mathrm{rad} / \mathrm{hr}$, $250 \mathrm{kV} x$-rays at $100 \mathrm{rad} / \mathrm{min}$, fission neutrons, and $\alpha$ particles. These curves may be used to determine the radiation dose to lymphocytes which are irradiated in vivo and this forms the basis of the biological dosimetry technique used in radiological protection. The relative frequency of the three unstable types of aberration varies with the radiation dose level as shown in Table I. At the two lower doses shown in the table the acentric yield exceeds that of the dicentrics but at higher doses this order is reversed and dicentrics predominate. Although 
$\Delta \propto$ particles (Vulpis, 1973)

$x$ fission neutrons

- $250 \mathrm{kV}$ x-rays (100 rad $/ \mathrm{min})$

- ${ }^{\circ} \mathrm{Co} \gamma$-rays (18 rad/hr)

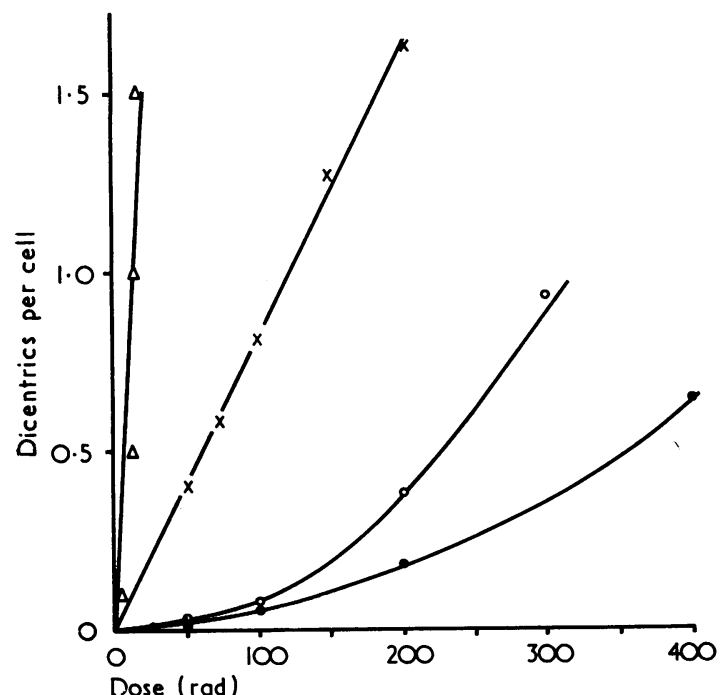

Fig. 3. Dicentric yields in peripheral blood lymphocytes plotted against dose for four types of radiation delivered in vitro.

TABLE I

THE IN-VITRO YIELD OF THREE TYPES OF ABERRATION IN PERIPHERAL BLOOD LYMPHOCYTES AT SEVEN DIFFERENT DOSES OF $250 \mathrm{kV}$ X-RAYS

\begin{tabular}{c|c|c|c|c}
\hline Dose (rad) & $\begin{array}{c}\text { Cells } \\
\text { Scored }\end{array}$ & Dicentrics & $\begin{array}{c}\text { Centric } \\
\text { Rings }\end{array}$ & Acentrics \\
\cline { 2 - 3 } & 2070 & 50 & 3 & 71 \\
50 & 872 & 73 & 1 & 81 \\
200 & 500 & 191 & 11 & 150 \\
300 & 305 & 283 & 21 & 157 \\
400 & 200 & 252 & 11 & 185 \\
500 & 60 & 143 & 12 & 97 \\
700 & 42 & 178 & 10 & 97 \\
\hline
\end{tabular}

in the past most of the biological dosimetry has been done with dicentric data, in the future more attention will have to be paid to acentrics, particularly at lower radiation doses.

By means of animal experiments (Clemenger and Scott, 1971; Preston, Brewen, and Jones, 1972) it has been well established that aberration yields in lymphocytes following uniform whole body radiation are the same as those obtained when blood samples from the animals are irradiated to the same dose levels in vitro. This type of information is more difficult to obtain for human lymphocytes. However, Buckton et al (1971) reported that within the limits of experimental error, the in-vivo and invitro aberration yields in lymphocytes were the same for humans. In this study patients were treated with a uniform whole body exposure of 25 or $50 \mathrm{rad}$ from a $2 \mathrm{MeV} x$-ray source.

In Table I it is worth noting that a large number of cells must be scored to obtain statistically meaningful data especially when studying the relatively low yields associated with low radiation doses. Unfortunately much work has been published in which the statistical accuracy is so low that subsequent interpretation is very uncertain.

\section{Identifying and Scoring Aberrations}

In the National Radiological Protection Board (NRPB) laboratory the slides are stained with lacto acetic orcein and examined under high power with bright field illumination or phase contrast, depending very much on the personal preference of the scorer. The aberrations are identified under the microscope and photographs are not normally used for this purpose. The criteria for scoring aberrations are the presence of 46 centromeres and the presence of the appropriate fragments for any dicentrics or centric rings observed. Cells are selected for quality by scanning the slide at low magnification $(\times 120)$ and are then scored under high magnification $(\times 800)$. If on first inspection under high magnification there is too much overlap of the chromosomes, or the two chromatids are not clearly discernible, the cell is rejected. Naturally there is a considerable degree of subjective judgement in the selection of cells but in the statistical tests that have been carried out between scorers in the NRPB Laboratory this is found to be insignificant.

The above scoring procedure is used in experiments where the blood is irradiated in vitro but for in-vivo irradiation two or more divisions of irradiated precursor cells may have occurred before the lymphocyte is observed, hence it may contain dicentrics and rings without fragments; these cells are not rejected (Lloyd, Purrott, and Dolphin, 1973a). Their presence can only be explained by assuming that in a minority of damaged cells the deletion of material is not sufficiently serious to prevent formation of viable daughter cells.

Recently an NRPB scorer with only one year's experience participated in an international collaborative study (Abbatt, 1971). Only preliminary data are available but in analysing cells previously selected by the organizers she was in good agreement with the three most experienced and proficient scorers. Naturally there was not complete agreement among all participants, even the most experienced ones. In the quantitative use of aberration yields, the statistical errors due to the random 
production of aberration in cells are likely to mask any small differences due to mistaken identification, provided the scorer is not systematically misidentifying a particular type of aberration; but this is unlikely in our experience.

Another check on the reliability of scoring was made in a recent joint study of blood samples from irradiated patients which were divided between the NRPB Laboratory and the MRC Population Genetics Unit at Oxford (Stevenson et al, 1973). In only three of the 70 patients investigated was the disagreement between the two laboratories in chromosome aberration scores unacceptably large. This high degree of agreement was obtained even though different culture techniques were used in the two laboratories and no intercomparison tests were carried out before starting the project-only the scoring criteria were common to both. This again confirms that the scoring techniques are reliable and are neither overwhelmingly difficult nor lacking in precision.

\section{Lymphocyte Culture Techniques}

These are based on the method of Moorhead et al, 1960. In essence the technique for lymphocytes is to stimulate them with a mitogen such as phytohaemagglutinin (PHA) and to incubate the cells in culture at $37^{\circ} \mathrm{C}$ for between 48 and 52 hours. At longer times cells may reach second division in culture and this must be avoided for biological dosimetry purposes (Buckton and Pike, 1964; Heddle, Evans, and Scott, 1967). There are three basic methods, namely macro, mini, and micro cultures. In the macro technique, serum from the patient's own blood is used in the culture and hence this method has the disadvantage as it requires relatively large blood samples of the order of $20 \mathrm{ml}$. In the mini culture technique, used in our laboratory, lymphocytes are separated from $1 \mathrm{ml}$. of blood by gentle centrifugation following the addition of PHA, and the cells are cultured in a mixture of a synthetic medium and a natural serum. In the micro technique, $0.25 \mathrm{ml}$. of whole blood, which may be obtained from a finger prick, is cultured in the same medium and serum mixture for mini cultures. The methods of culture and slide preparation used in this laboratory have been described in detail by Purrott and Lloyd (1972).

\section{Lymphocytes in Humans}

One of the major sources of uncertainty in interpreting aberration yields in terms of radiation dose following in-vivo irradiation is the lack of knowledge concerning lymphocyte kinetics in humans. This is particularly pertinent in those cases of human radiation exposure which occurred many years ago or where the irradiation followed a chronic course.

Much attention has been given to the study of the lymphocyte in the last few years and now two types have been identified, $T$ and $B$. The former are dependent on the thymus and the latter on the avian bursa equivalent, probably bone marrow in rodents and man. It has now been recognized that only the T lymphocytes can be stimulated by PHA and there is a suggestion that the $\mathrm{B}$ cells may respond to other mitogens (Raff, 1973).

Chromosome aberrations have been used to label lymphocytes and it is possible to study lymphocyte kinetics in humans given extracorporeal irradiation for leukaemia or immunological suppression. Data reported by Sharpe et al (1967) show that the lymphocytes have a mean residence of a few minutes in the peripheral circulation because they rapidly exchange into the pool of lymphocytes in the body. The total mass of $T$ lymphocytes in this pool is of the order of $300 \mathrm{~g}$. Field et al (1972) later showed that irradiated lymphocytes did not reach metaphase in culture as readily as unirradiated cells so that the original work with extracorporeal irradiation has to be modified to take this fact into account.

Lloyd, Purrott, and Dolphin (1973b) have made a quantitative study of interphase death of irradiated lymphocytes which indicates a $D_{37}$ value of about $270 \mathrm{rad}$ and thus cell death must be taken into account if cultures are made of mixtures of irradiated and unirradiated cells as could occur naturally in a peripheral blood sample from a person exposed to partial body irradiation.

Studies of the disappearance of aberrations from peripheral blood lymphocytes indicate that these cells have a half-life of several years (Norman et al, 1966; Buckton, Smith, and Court Brown, 1967). Aberrations which may be attributed to the atomic radiation could be detected in survivors of Hiroshima and Nagasaki 20 years afterwards (Bloom et al, 1966). The long half-life is an advantage in assessing the radiation dose to a person exposed chronically for a number of years. However, there is still much uncertainty about the half-life of the lymphocyte and how it depends on the health of the individual person (Fitzgerald, 1967).

\section{Observation of Chromosome Aberrations in Other Tissues}

Chromosome damage resulting from radiation injury may be demonstrated in other somatic tissues apart from peripheral blood lymphocytes. These are tissues which normally have a high mitotic rate 
such as bone marrow (Tjio and Whang, 1965), skin fibroblasts (Harnden and Brunton, 1965), hair follicles (Daker, 1970) and corneal epithelium (Fredga, 1964), and tissues such as liver (Brooks and Mead, 1969) which can be stimulated-by partial hepatectomy-to produce many mitoses.

These systems suffer from several disadvantages compared with the lymphocyte. Most are more difficult to biopsy than a simple blood sample. In the case of the normally dividing tissues the cells are not in synchrony. Cells vary in radiosensitivity at different stages of the cell cycle and the types of aberrations produced depend on the position of the cell in the cycle at the time of the radiation insult (Evans, 1970). Hence when an unsynchronous cell population is irradiated a heterogeneous collection of aberrations is seen making quantitative analysis very difficult. Marrow and hair follicle cells may be examined in direct preparations, whilst fibroblasts need relatively long-term culturing. In both instances the cells when harvested are no longer in their first, post-irradiation division. Cells carrying chromosome aberrations are more likely to be eliminated at division than undamaged cells so that following several divisions either in vivo or in vitro the cell population observed is not representative of the original due to this selective elimination. In addition some of the chromosome aberrations which survive to be seen are of the derived type, originating from chromatid damage (Evans, 1970). All this will quite clearly complicate any attempt to carry out quantitative work with these tissues.

A question frequently asked by male radiation workers who have received an accidental overexposure concerns the prospect of genetic damage to their future offspring. In principle testicular biopsy material could be examined for chromosome abnormalities. Methods for this test have been described (Ohno, 1965) using tissues from animal and human gonads from abortuses. However, this procedure will never give an unequivocal answer because the absence of visible chromosome damage may still not ensure the absence of genetic damage in the offspring, nor will the presence of some chromosome anomalies in germ cells necessarily indicate a genetically deformed child.

\section{Some Applications of Chromosome Aberration Studies in Radiobiology}

Radiological Protection. During the rapid expansion in the development and the use of atomic energy during the last 20 years much thought has been given to the problems of estimating the dose to persons involved in large radiation accidents, such as the ones which occurred at Oak Ridge, USA and
Vinca, Yugoslavia in 1958 (Andrews, 1962). It was recognized that a reliable biological system was necessary to supplement dose information from the physical systems. Initially biochemists expended much effort trying to relate radiation breakdown products excreted in urine, such as $\beta$-aminoisobutyric acid (a breakdown product of thymidine) and other intermediate or end products of nucleic acid and protein metabolism, with radiation dose to the whole body. However, this was not successful for although radiation caused breakdown of biochemicals, these breakdown products were usually swamped by the natural variations in their production and excretion (Dolphin, 1968). During the last five years most scientists concerned with radiological protection have accepted that the yield of chromosome aberrations in peripheral blood lymphocytes is the best available parameter for biological dosimetry. In the event no major radiation accident has occurred in the last five years so the value of this technique has not yet been tested.

As major radiation accidents are fortunately infrequent the part played by chromosome aberration analysis in radiological protection is considerably different from that originally envisaged. Purrott et al $(1972 ; 1973)$ have reported on 95 cases in which blood samples, mostly from industrial radiographers, have been received for chromosome aberration analysis. More than three-quarters of the cases investigated came to notice because the dose recorded by the film badge was doubted for one or more of several reasons, such as inadvertent exposure whilst not being worn, non-uniform irradiation, or film blackening caused by heat or chemical contamination. In these cases it is important to resolve the doubt, for the future employment of the radiographer may be at stake or considerable personal anxiety may be involved. There are a few cases which came to light where exposure is known or thought to have occurred but no film badge was worn and here chromosome aberration analysis is the only method of dose assessment currently available.

A major limitation of the technique is the lower level of dose detection which is about $25 \mathrm{rad}$ of $\mathrm{X}$ or $\gamma$ radiation to the whole body. When automatic equipment becomes available for aberration analysis this limit may be lowered because it should become possible to examine several thousand cells per blood sample. At present only 200-500 cells are examined and this involves at least two man-days of microscope work. The background frequency of dicentrics is fortunately very low in the unirradiated general population. Evans (1970), reviewing several workers' control data, has calculated 1 dicentric per 
4000 cells whilst the incidence of acentric aberrations is somewhat higher.

Nevertheless chromosome and, more particularly, chromatid damage is certainly produced by other non-radiological agents in the environment. However much of this damage has only been demonstrated for certain in vitro at mutagen concentrations well above those experienced by lymphocytes in vivo. Lysergic acid diethylamide (LSD) (Dishotsky et al, 1971) and caffeine (Bishun, Williams, and Raven, 1973) are good examples of drugs where the in-vivo results are conflicting. Shaw (1970) has written a comprehensive review of the chromosomolytic effects of chemicals and Nichols (1970) has reviewed the work on the interaction of viruses with chromosomes. In general it is considered that viruses act like the chemical mutagens in disrupting DNA synthesis, resulting in the main in chromatid damage which is only expressed as chromosome aberrations of the derived type (Evans, 1970). Thus previous exposure to many of the viral or chemical agents does not tend to cause background aberrations conflicting with those induced by radiation provided one works with peripheral blood lymphocytes, as these cells, once formed, remain in $\mathrm{G}_{0}$ until brought to metaphase in culture.

In radiological protection the objective is to limit radiation exposure so that the risk of late biological effects is acceptably low. At present there is no relationship between the chromosome damage observed after irradiation and the risk of late biological effects.

In this work on suspected or real radiation overexposure $6 \mathrm{ml}$. blood samples are dispatched to the NRPB Laboratory through the express post in radiation-sterilized plastic tubes with lithium heparin coated on the walls. Experiments have previously been carried out in the Laboratory which indicate that at dose levels below $100 \mathrm{rad}$ the aberration yield is not affected if the blood is held at room temperature for up to six days before culture. A blood sample from the Middle East and several from Europe, dispatched by air, have been successfully cultured in the Laboratory.

Radiotherapy Patients. One form of treatment for rheumatoid conditions of the joints, particularly the knee, is intra-articular injection of radiogold or radioyttrium. A survey was carried out on 70 patients receiving this form of treatment (Stevenson et al, 1973). In the majority of patients only a small aberration yield was found but in a few a large amount of damage was observed, the highest being 28 dicentrics per 100 cells. From the in-vitro calibration curves this high yield corresponds to an equivalent whole body dose of about $250 \mathrm{rad}$ but such a dose is not possible from the amount of radionuclide initially injected. Typically the ininjection was $10 \mathrm{mCi}$ of ${ }^{198}$ gold or $5 \mathrm{mCi}$ of ${ }^{90} \mathrm{yttrium}$ which, when spread uniformly throughout the body, would give a dose of just over $10 \mathrm{rad}$.

These high aberration yields were found to correlate with the amount of radiogold leaking from the joint and passing along the lymphatic ducts to the inguinal lymph nodes where it was measured by scintillation scanning techniques. This correlation led Stevenson et al (1973) to suggest that the high aberration yield was due to selective irradiation of the lymphocytes as they passed through the lymph nodes containing the radiogold. On a quantitative basis data were consistent with about $50 \mathrm{~g}$ of lymphocytes circulating through these regional lymph nodes during the week or so required for most of the ${ }^{198}$ gold to decay and in a single transit these lymphocytes received a dose of about $400 \mathrm{rad}$. In this work the lymphocytes were stimulated into division by PHA so these data refer to $T$ cells.

In 1961, Pochin drew attention to the increased incidence of leukaemia in a group of about 200 patients treated for thyroid cancer by radioiodine. This excess leukaemia, which was noted in the 20 years following treatment, may be associated with whole body radiation doses from the radioiodine and in order to assess the risk it is important to make a reliable estimate of the total body dose involved in the treatment. Although the metabolism of iodine in humans is reasonably well understood, the calculation of whole body radiation dose still presents problems. In cooperation with Halnan and his colleagues at the Institute of Radiotherapeutics, Glasgow, it was decided to make a biological estimate of equivalent whole body dose from chromosome aberration analysis and to compare this with physical estimates in a number of patients given $80 \mathrm{mCi}$ of ${ }^{131}$ iodine for thyroid ablation or $200 \mathrm{mCi}$ for treatment of metastatic deposits following ablation. Preliminary results (Lloyd et al, in preparation) indicate reasonably good agreement in dose calculations in those patients studied after the thyroid had been ablated but in the small number of patients where the thyroid was present at the time of administration the biological dose estimate was up to three times higher than the physical estimate. More work must be done to find out whether this discrepancy is due to an under-estimate of the physical dose, or a falsely high value of biological dose due to selective $\beta$ irradiation of the lymphocytes as they pass through tissues with high concentrations of ${ }^{131}$ iodine.

Clearly it would be of considerable interest to 
observe the chromosome aberration yield in lymphocytes from radiotherapy patients to ascertain whether the yield varies from patient to patient given the same treatment regime. A longterm follow-up in cases where the cure rate is high or the disease treated is not terminal might reveal whether there is a relationship between the acute radiation effects observed in chromosomes and late biological effects such as cancer or life shortening.

Chromosome Aberrations Produced by Negative $\pi$ Mesons. In recent years much interest has developed in the possible use of negative $\pi$ mesons (pions) in radiotherapy (Raju and Richman, 1972). With pions one is able to deliver a dose peak to a tumour $10-20 \mathrm{~cm}$ deep and this is two to three times greater than the dose to skin and intervening tissues. Behind the peak the dose falls off sharply. In addition there is a preponderance of high LET radiation in the peak. These characteristics of the beam make it very attractive to radiotherapists. A pion beam is currently available from the $7 \mathrm{GeV}$ Nimrod Accelerator at the Rutherford High Energy Laboratory, Harwell (Perry and Hynes, 1971), which produces dose rates up to 80 $\mathrm{rad} / \mathrm{hr}$ in unit density material. Chromosome aberration yields in lymphocytes have proved to be a very satisfactory biological system for investigating the damage profile in a tissue equivalent phantom. Initial results with a $70 \mathrm{MeV}$ pion beam indicate a ratio of chromosome damage in the peak to that at the surface of about 2.6 for two nominal peak doses of 100 and $360 \mathrm{rad}$. This value is a little less optimistic than theoretical estimates which predicted a value close to 6 . More studies of the effect of dose rate and fractionation on aberration yield are underway.

\section{Conclusion}

During the last decade much has been achieved by studying aberration yields in irradiated tissues and the signs are that more is to come in the next decade.

\section{REFERENCES}

Abbatt, J. D. (1971). Cytogenetic indicators of radiation (and other) damage-calibration-present and future practical applications. In Biochemical Indicators of Radiation Injury in Man, pp. 149-180. IAEA, Vienna.

Andrews, G. A. (1962). Criticality accidents in Vinca, Yugoslavia and Oak Ridge, Tennessee. Fournal of the American Medical Association, 179, 191-197.

Bishun, N. P., Williams, D. C., and Raven, R. W. (1973). Chromosome damage to HeLa cells grown continuously in caffeine. Mutation Research, 17, 145-146.

Bloom, A. D., Neriishi, S., Kamasa, N., Iseki, T., and Keehn, R. J. (1966). Cytogenetic investigations of survivors of the atomic bombings of Hiroshima and Nagasaki. Lancet, 2, 672-674.

Brooks, A. L. and Mead, D. K. (1969). The metaphase chromosomes of Chinese hamster liver cells following partial hepatectomy. Canadian fournal of Genetics and Cytology, 11, 794-798.
Buckton, K. E., Langlands, A. O., Smith, P. G., Woodcock, G. E,. Looby, P. C., and McLelland, J. (1971). Further studies on chromosome aberration production after whole-body irradiation in man. International fournal of Radiation Biology, 19, 369-378.

Buckton, K. E. and Pike, M. C. (1964). Chromosome investigations on lymphocytes from irradiated patients. The effect of time in culture. Nature, 202, 714-715.

Buckton, K. E., Smith, P. G., and Court Brown, W. M. (1967). The estimation of lymphocyte lifespan from studies on males treated with X-rays for ankylosing spondylitis. In Human Radiation Cytogenetics, ed. by H. J. Evans, W. M. Court Brown, and A. S. McLean, pp. 106-114. North-Holland, Amsterdam.

Clemenger, J. F. and Scott, D. (1971). In vitro and in vivo sensitivity of cultured blood lymphocytes to radiation induction of chromosome aberrations. Nature New Biology, 231, 154.

Daker, M. G. (1970). Chromosome from hairs. Lancet, 1, 1174.

Dishotsky, N. I., Loughman, W. D., Mogar, R. E., and Lipscomb, W. R. (1971). LSD and genetic damage. Science, 172, 431-440. Dolphin, G. W. (1968). Biological monitoring for dose assessment following accidental intake of radioactive materials. In Proceedings of the International Symposium on Accidental Irradiation at Place of Work, pp. 195-202. Euratom 3666, Brussels.

Evans, H. J. (1970). Population cytogenetics and environmental factors. In Human Population Cytogenetics, ed. by P. A. Jacobs, W. H. Price, and P. Law, pp. 191-216. University of Edinburgh Press.

Field, E. O., Sharpe, H. B. A., Dawson, K. B., Andersen, V., Killman, S. A., and Weeke, E. (1972). Turnover rate of normal blood lymphocytes and exchangeable pool size in man, calculated from analysis of chromosomal aberrations sustained during extracorporeal irradiation of the blood. Blood, 39, 39-56.

Fitzgerald, P. H. (1967). The life-span and role of the small lymphocyte. In Human Radiation Cytogenetics, ed. by $\mathrm{H}$. J. Evans, W. M. Court Brown, and A. S. McLean, pp. 94-98. North-Holland, Amsterdam.

Fredga, K. (1964). A simple technique for demonstration of the chromosomes and mitotic stages in a mammal. Chromosomes from cornea. Hereditas, Genetiskt Arkiv, 51, 268-273.

Giles, N. H. (1954). Radiation-induced chromosome aberrations in Tradescantia. In Radiation Biology, ed. by A. Hollaender, vol. 1, pt. 2, pp. 713-761. McGraw-Hill, London.

Green, D. K. and Cameron, J. (1972). Metaphase cell finding by machine. Cytogenetics, 11, 475-487.

Harnden, D. G. and Brunton, S. (1965). The skin culture technique. In Human Chromosome Methodology, ed. by J. J. Yunis, pp. 57-73. Academic Press, London.

Heddle, J. A., Evans, H. J., and Scott, D. (1967). Sampling time and the complexity of the human leukocyte culture system. In Human Radiation Cytogenetics, ed. by H. J. Evans, W. M. Court Brown, and A. S. McLean, pp. 6-19. North-Holland, Amsterdam.

Lea, D. E. (1946). Actions of Radiations on Living Cells. Cambridge University Press, London.

Lloyd, D. C., Purrott, R. J., and Dolphin, G. W. (1973a). Chromosome aberration dosimetry in a case of over-exposure to radiation. Nature, 2A1, 69-70.

Lloyd, D. C., Purrott, R. J., and Dolphin, G. W. (1973b). Chromosome aberration dosimetry using human lymphocytes in simulated partial body irradiation. Physics in Medicine and Biology, 18, 421-431.

Moorhead, P. S., Nowell, P. C., Mellman, W. J., Battips, D. M., and Hungerford, D. A. (1960). Chromosome preparations of leukocytes cultured from human peripheral blood. Experimental Cell Research, 20, 613-616.

Nichols, W. W. (1970). Virus-induced chromosome abnormalities Annual Review of Microbiology, 24, 479-500.

Norman, A., Sasaki, M. S., Ottoman, R. E., and Fingerhut, A. G (1966). Elimination of chromosome aberrations from human lymphocytes, Blood, 27, 706-714.

Ohno, S. (1965). Direct handling of germ cells. In Human Chromosome Methodology, ed. by J. J. Yunis, pp. 75-90. Academic Press, London.

Pearson, P. (1972). The use of new staining techniques for human chromosome identification. Fournal of Medical Genetics, 9, 246275.

Perry, D. R. and Hynes, M. A. (1971). A pion beam for radio- 
biological and dosimetric studies, using a proton synchrotron external target. In Proceedings of the International Congress on Protection against Accelerator and Space Radiation, vol. 1, pp. 220230. CERN (71-16), Geneva.

Pochin, E. E. (1961). The occurrence of leukaemia following radioiodine therapy. In Advances in Thyroid Research, ed. by $\mathbf{R}$. Pitt-Rivers, pp. 392-397. Pergamon Press, London.

Preston, R. J., Brewen, J. G., and Jones, K. P. (1972). Radiationinduced chromosome aberrations in Chinese hamster leukocytes. A comparison of in vivo and in vitro exposures. International Fournal of Radiation Biology, 21, 397-400.

Purrott, R. J., Dolphin, G. W., Lloyd, D. C., Rickard, B., and Eltham, E. (1972). The study of chromosome aberration yield in human lymphocytes as an indicator of radiation dose. II. A review of cases investigated: 1970-71. National Radiological Protection Board Report Series, NRPB-R5. HMSO, London.

Purrott, R. J. and Lloyd, D. C. (1972). The study of chromosome aberration yield in human lymphocytes as an indicator of radiation dose. I. Techniques. National Radiological Protection Board Report Series, NRPB-R2. HMSO, London.

Purrott, R. J., Lloyd, D. C., Dolphin, G. W., Eltham, E. J., Platt, S. K., Tipper, P. A., and Strange, C. M. (1973). The study of chromosome aberration yield in human lymphocytes as an indicator of radiation dose. III. A review of cases investigated: 197172. National Radiological Protection Board Report Series, NRPB-R10. HMSO, London.
Raff, M. C. (1973). T and B lymphocytes and immune responses. Nature, 242, 19-23.

Raju, M. R. and Richman, C. (1972). Negative pion radiotherapy: physical and radiobiological aspects. Current Topics in Radiation Research Quarterly, 8, 159-233.

Sax, K. (1938). Chromosome aberrations induced by X-rays. Genetics, 23, 494-516.

Sharpe, H. B. A., Dolphin, G. W., Dawson, K. B., and Field, E. O. (1967). Chromosome aberration in lymphocytes from an extracorporeally irradiated patient. Lancet, 2, 1338-1339.

Shaw, M. W. (1970). Human chromosome damage by chemical agents. Annual Review of Medicine, 21, 409-432.

Stevenson, A. C., Bedford, J., Dolphin, G. W., Purrott, R. J., Lloyd, D. C., Hill, A. G. S., Hill, H. F. H., Gumpel, J. M., Williams, D., Scott, J. T., Ramsey, N. W., Bruckner, F. E., and Fearn, C. B. D'A. (1973). Cytogenetic and scanning study of patients receiving intra-articular injections of gold-198 and yttrium-90. Annals of the Rheumatic Diseases, 32, 112-123.

Tjio, J. H. and Whang, J. (1965). Direct chromosome preparations of bone marrow cells. In Human Chromosome Methodology, ed. by J. J. Yunis, pp. 51-56. Academic Press, London.

Vulpis, N. (1973). Chromosome aberrations induced in human peripheral blood lymphocytes using heavy particles from ${ }^{10} \mathrm{~B}(\mathrm{n}, \alpha)^{7} \mathrm{Li}$ reaction. Mutation Research, 18, 103-111.

Wolff, S. (1972). The repair of X-ray induced chromosome aberrations in stimulated and unstimulated human lymphocytes. Mutation Research, 15, 435-444. 